Review

\title{
Recent progress of catalytic pyrolysis of biomass by HZSM-5
}

\author{
TAN Shun a , ZHANG Zhijun a, SUN Jianping a,b, WANG Qingwen ${ }^{\text {a,* }}$ \\ a Key Laboratory of Bio-based Material Science and Technology, Ministry of Education, Northeast Forestry University, Harbin 150040, Heilongjiang, China \\ ${ }^{\mathrm{b} S}$ Shool of Municipal and Environmental Engineering, Shenyang Jianzhu University, Shenyang 110168, Liaoning, China
}

\section{A R T I C L E I N F O}

\section{Article history:}

Received 10 November 2012

Accepted 7 January 2013

Published 20 April 2013

Keywords:

Biomass

Bio-oil

Upgrading

Cracking

Pyrolysis

HZSM-5

\begin{abstract}
A B S T R A C T
Biomass can be converted into a variety of fuels and chemicals using different technologies. One such process is fast pyrolysis, which is convenient for the conversion of biomass primarily into liquid products known as bio-oils. These bio-oils, however, must be upgraded if they are to be used as a replacement for diesel and gasoline fuels. At present, when improving the quality of bio-oils, catalytic vapor cracking is generally considered superior to other catalytic upgrading technologies, such as hydrotreating and esterification. This review summarizes the current status of research concerning both the catalytic pyrolysis of biomass and the catalytic cracking of bio-oil using the zeolite HZSM-5, focusing on the specific catalysts employed, as well as the upgrading methods and reaction mechanisms.
\end{abstract}

(C) 2013, Dalian Institute of Chemical Physics, Chinese Academy of Sciences. Published by Elsevier B.V. All rights reserved.

\section{Introduction}

Biomass is a renewable energy source which offers a number of social, political, and economic advantages compared with other fuels. The increasing concerns regarding potential fossil fuel shortages and the environmental problems associated with their use ensure that renewable biomass resources will undoubtedly play an increasingly important role in the future [1]. Various processes may be employed to convert biomass into useful fuels and chemicals. One such technique, fast pyrolysis, offers a ready means to convert biomass into liquid bio-oils [2].

The fast pyrolysis processes by which bio-oils are produced from biomass are typically carried out in the absence of air at relatively low temperatures of 450 to $550{ }^{\circ} \mathrm{C}$, employing high heating rates $\left(10^{3}-10^{4} \mathrm{~K} / \mathrm{s}\right)$ and short gas residence times to crack organic compounds into short chain molecules followed by rapid cooling to the liquid state [3]. Fast pyrolysis is very effective for the conversion of biomass, producing liquid fuels which are readily stored and transported at high yields of up to
$70 \%-80 \%$ and high fuel to feed ratios. Consequently the creation of fuel oils from biomass in this manner is regarded as one of the most likely technologies to compete with and eventually replace non-renewable fossil fuel resources [4].

In general, bio-oil consists of a wide variety of organic compounds, and can be roughly defined as a mixture of carboxylic acids, alcohols, aldehydes, alkenes, esters, furans, ketones, phenols, and sugars [5]. The major drawbacks of bio-oil are its high level of oxygenation, high viscosity, corrosiveness, and relatively poor stability. In addition, the relatively high concentrations of both water and oxygenated compounds in bio-oil reduce its calorific value and can significantly change its combustion characteristics [6-9]. Finally, the presence in bio-oil of certain undesirable oxygenated compounds, such as organic acids and carbonyls, as well as polycyclic aromatic hydrocarbons, limits its potential for direct use in engines or turbines. Basic physical property data for both bio-oil and conventional petroleum fuel are compared in Table 1.

As noted earlier, bio-oils must be upgraded if they are to be

\footnotetext{
*Corresponding author. Tel: +86-451-82191993; Fax: +86-451-82191993; E-mail: qwwang@nefu.edu.cn This work was supported by the National Natural Science Foundation of China (31010103905). 
Table 1

Typical properties of wood-derived pyrolysis bio-oil and heavy fuel oil [3].

\begin{tabular}{|c|c|c|c|c|c|c|c|c|c|c|c|c|}
\hline \multirow{2}{*}{ Oil } & \multirow{2}{*}{$\begin{array}{c}\text { Moisture } \\
\text { content (wt } \%)\end{array}$} & \multirow{2}{*}{$\mathrm{pH}$} & \multirow{2}{*}{$\begin{array}{l}\text { Specific } \\
\text { gravity }\end{array}$} & \multicolumn{5}{|c|}{ Elemental composition (wt\%) } & \multirow{2}{*}{$\begin{array}{c}\begin{array}{c}\mathrm{HHV} \\
(\mathrm{MJ} / \mathrm{kg})\end{array} \\
\end{array}$} & \multirow{2}{*}{$\begin{array}{c}\text { Viscosity at } \\
500{ }^{\circ} \mathrm{C}(\mathrm{mPa} \cdot \mathrm{s}) \\
\end{array}$} & \multirow{2}{*}{$\begin{array}{c}\text { Solid } \\
\text { (wt\%) }\end{array}$} & \multirow{2}{*}{$\begin{array}{c}\text { Distillation } \\
\text { residue (wt } \%) \\
\end{array}$} \\
\hline & & & & $\mathrm{C}$ & $\mathrm{H}$ & 0 & $\mathrm{~N}$ & Ash & & & & \\
\hline & $15-30$ & 2. & 1.20 & $54-58$ & 7 & 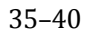 & 0.2 & $0-0.2$ & $16-19$ & $40-100$ & $0.2-1.0$ & up to 50 \\
\hline Heavy fuel oil & 0.1 & - & 0.94 & 85 & 11 & 1.0 & 0.3 & 0.1 & 40 & 180 & 1.0 & 1 \\
\hline
\end{tabular}

used as replacements for diesel and gasoline fuels. The existing methods for improving the yield of high quality bio-oil can, in general, be placed in one of two categories: the methods which rely on physical upgrading (hot-gas filtration, emulsification and solvent addition) and those which employ catalytic upgrading (hydrotreating, steam reforming, and catalytic vapor cracking) [10]. Since the latter techniques result in significant improvements ranging from simple stabilization to high quality fuel products, the majority of studies to date have focused on catalytic upgrading, even though it is more complex and more expensive than the physical methods [11-13]. Studies concerning chemical upgrading via the use of catalysts, however, have primarily focused on catalytic vapor cracking rather than hydrotreating, since vapor cracking does not require the use of hydrogen and may be performed under atmospheric pressure, thus reducing operating costs. The various biomass conversion processes are summarized in Fig. 1.

Over the last few decades, fast pyrolysis has been extensively studied as one of the most promising technologies for biomass conversion and many reviews on this subject have been published, but few comprehensive reviews on the catalytic pyrolysis of biomass with HZSM-5 have appeared, especially with regard to the upgrading of bio-oil [14-17]. In this review, recent results and trends in both biomass catalytic pyrolysis and bio-oil catalytic upgrading over HZSM-5 are summarized, focusing on the particular catalysts applied, the upgrading methods, and the reaction mechanisms.

\section{Catalytic pyrolysis of biomass}

Based on the positioning of the catalyst within the reactor, catalytic pyrolysis can be divided into two different processes: in-situ and in-bed $[18,19]$. In the in-situ process, the biomass is cracked to produce pyrolytic vapors which pass through catalyst beds where they are converted into bio-oil as well as gaseous and solid byproducts. During the in-bed process, catalytic pyrolysis occurs in a reactor where biomass feedstocks and catalysts are mixed together to allow for direct contact between the two. The in-situ process has the drawback of usually producing greater quantities of water and coke, which in turn decreases the yield of liquid bio-oil. The advantage of the in-situ process is that the catalytic temperature and pyrolysis temperature are independently controllable, which allows for increased control over the product component proportions. A variety of examples of the catalytic pyrolysis of biomass conducted under different reaction conditions are summarized in Table 2.

\subsection{Different types of biomass}

Wood and other plant biomass is essentially a composite material composed of oxygen-containing organic polymers. The major components are cellulose, hemicelluloses, lignin, organic extractives, and inorganic minerals. The weight percentages of cellulose, hemicelluloses, and lignin vary between biomasses based on different species of wood. The pyrolysis of each of these components is itself a complex process that is potentially affected by numerous factors and, as such, different types of biomass will produce different bio-oils, although the main properties of the oils will be similar [3]. A summary of the main steps in the reaction chemistry associated with the catalytic fast pyrolysis of biomass is presented in Fig. 2 .

Many papers have reported the conversion of biomass to aromatics. Pattiya et al. [20] investigated the catalytic pyrolysis of cassava rhizome and found that all of the catalysts which they applied assisted in producing aromatic hydrocarbons and reducing the formation of oxygenated lignin derivatives, leading to an improvement in the bio-oil's heating value and viscosity. This same group also investigated the catalytic pyrolysis of cassava rhizome at $500{ }^{\circ} \mathrm{C}$ and demonstrated that the use of ZSM-5, Criterion-534, and Al-MSU-F catalysts enhanced the formation of aromatic hydrocarbons and phenols [26]. Carlson et al. [21] studied the production of aromatics from glucose by catalytic fast pyrolysis. The aromatic product selec-

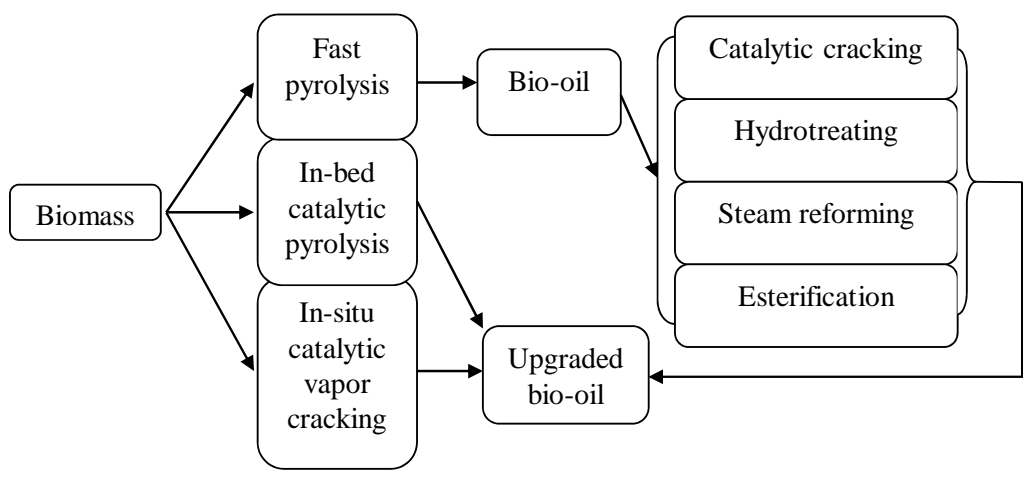

Fig. 1. Biomass conversion processes. 
Table 2

Catalytic pyrolysis of biomass under different reaction conditions.

\begin{tabular}{|c|c|c|c|c|}
\hline Feed & Catalyst & Temperature $\left({ }^{\circ} \mathrm{C}\right)$ & Type & Ref. \\
\hline Cassava rhizome & $\begin{array}{l}\text { ZSM-5, Al-MCM-41, Al-MSU-F, } \\
\text { alumina-stabilized ceria MI-575 }\end{array}$ & 500 & in-situ & {$[20]$} \\
\hline Glucose & ZSM-5 & $100-600$ & in-bed & [21] \\
\hline Glucose & $\begin{array}{l}\text { ZK-5, SAPO-34, Ferrierite, ZSM-23, MCM-22, SSZ-20, ZSM-11, } \\
\text { ZSM-5, IM-5, TNU-9, SSZ-55, Beta zeolite, Y zeolite }\end{array}$ & 600 & in-bed & [22] \\
\hline Corn stalks & ZSM-5, HY, USY & $400-600$ & in-situ and in-bed & [23] \\
\hline Pine wood & Beta, Y, ZSM-5 and Mordenite & 450 & in-situ & {$[24]$} \\
\hline Glucose, furan and maple wood & Different types of ZSM-5 & 600 & in-bed & [25] \\
\hline Cassava rhizome & ZSM-5, Al-MCM-41, Al-MSU-F, Metal oxides & 500 & in-situ & [26] \\
\hline Rice husk pyrolytic lignin & ZSM-5, HZSM-5, $\beta$-zeolite, MCM-41, SBA-15 & 600 & in-situ & [27] \\
\hline Rapeseed cake and safflower oil & HZSM-5, Fe-ZSM-5, and H-Beta & 350,400 & in-bed & [28] \\
\hline Malaysian refuse derived fuels & $\begin{array}{l}\text { Y-zeolite, FCC, ZSM-5, Ni-Mo-catalyst, Co-Mo-catalyst, } \\
\text { Silica-alumina and alumina }\end{array}$ & 450 & in-bed & [29] \\
\hline $\begin{array}{l}\text { Oak, corn cob, corn stover, switchgrass, } \\
\text { cellulose, hemicellulose, and lignin }\end{array}$ & Ferrierite, Mordenite, Y, ZSM-5, Beta & 550 & in-bed & [30] \\
\hline Herb residue & ZSM-5, Al-SBA-15, and alumina & $350-550$ & in-bed & [31] \\
\hline Rice husk & ZSM-5 & $400-600$ & in-situ & [32] \\
\hline Cellulose & $\mathrm{HY}, \mathrm{NH}_{4}-\mathrm{Y}, \mathrm{NH}_{4}-\mathrm{ZSM}-5, \mathrm{SiO}_{2}, \mathrm{Al}_{2} \mathrm{O}_{3}, \mathrm{MgO}, \mathrm{TiSiO}_{4}, \mathrm{Al}_{2} \mathrm{O}_{3} \mathrm{TiO}_{2}$ & 500 & in-situ & [33] \\
\hline Green microalgae & HZSM-5 & $300-500$ & in-situ & [34] \\
\hline Lignocell HBS & USY, ZSM- 5 additive & $400-500$ & in-situ & [35] \\
\hline Corncob & HZSM-5 & 550 & in-situ & [36] \\
\hline Olive Residue & Clinoptilolite, ZSM-5, HY & $350-500$ & in-situ & {$[37]$} \\
\hline Beech wood & $\mathrm{FCC}, \mathrm{ZSM}-5, \mathrm{MgO}, \mathrm{Al}_{2} \mathrm{O}_{3} \mathrm{NiO}, \mathrm{CrO}_{2} / \mathrm{TiO}_{2}$ & 500 & in-situ & [38] \\
\hline Pine sawdust & HZSM-5, MMZZSM-5, MFI, Ga/MFI & 500 & in-situ & [39] \\
\hline Pubescens and LDPE & HZSM-5, Desilicated ZSM-5 zeolite & $450-470$ & in-situ & [40] \\
\hline Beech wood & HZSM-5, Silicalite, Al-MCM-41 & 500 & in-situ & [41] \\
\hline
\end{tabular}

tivity was found to be affected by the catalyst to glucose weight ratio, the heating rate, and the reaction temperature. At $600{ }^{\circ} \mathrm{C}$, a maximum carbon yield of $32 \%$ aromatics was realized after $240 \mathrm{~s}$ at a catalyst to feed ratio of 19 . The main reaction competing with the production of aromatics was the formation of coke, which is most likely formed by polymerization of furans on the external catalyst surfaces. Jae et al. [22] also investigated the conversion of glucose to aromatics and Foster et al. [25] studied the conversion of glucose, furan, and maple wood over different types of ZSM-5 catalysts in semi-batch and fixed-bed reactors. It was determined that the aromatic yield from glucose conversion goes through a maximum as a function of the ZSM-5 framework silica-to-alumina ratio.

Zhao et al. [27] reported a promising method for the production of aromatics from pyrolytic lignin (PL). Compared with the lignins derived from a pulping process, the PLs obtained

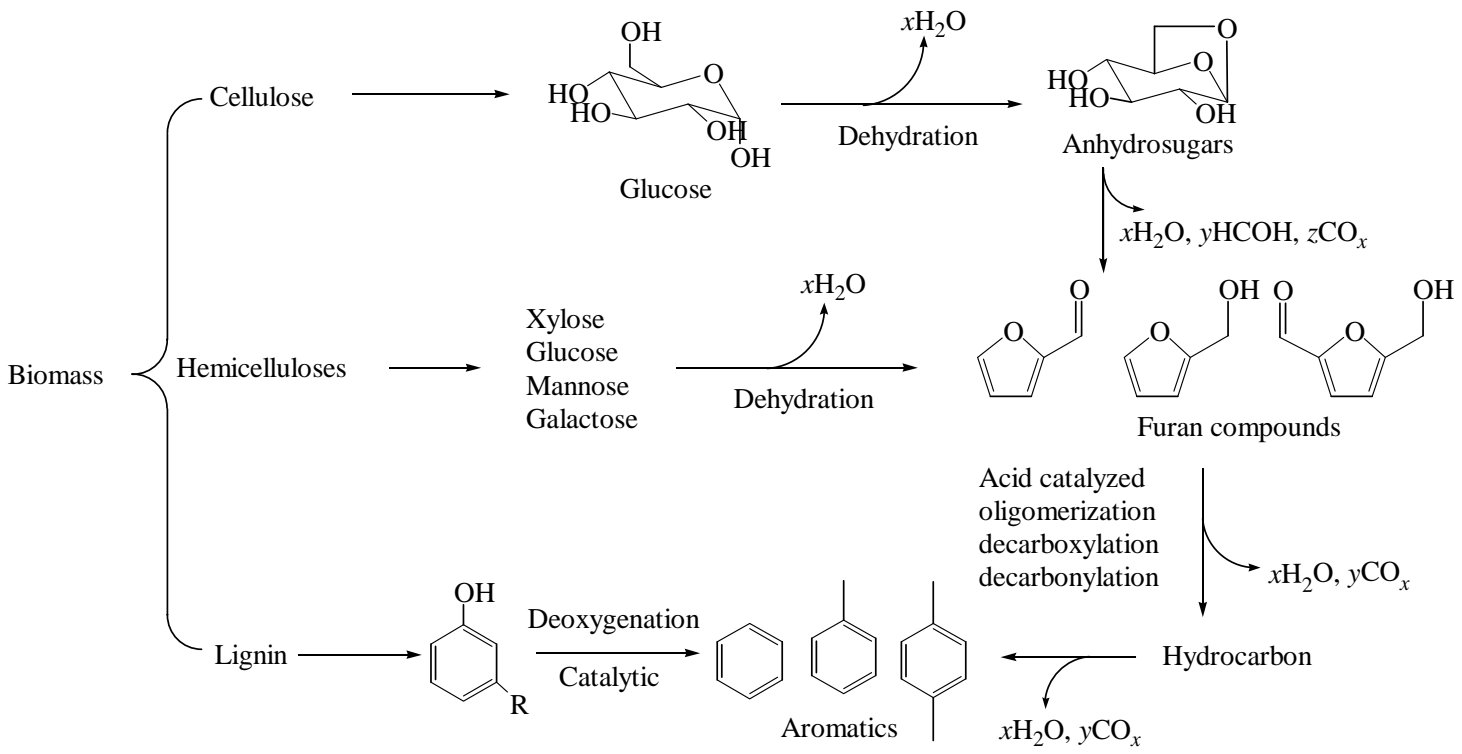

Fig. 2. Reaction chemistry of the catalytic fast pyrolysis of biomass [19,21]. 
from bio-oil produce more aromatics ( $40 \%$ in carbon yield) and do not generate effluvial gas containing sulfur. More importantly, phenols are the main products, with greater than $90 \%$ selectivity from reactions at $600{ }^{\circ} \mathrm{C}$ without a catalyst. Miskolczi et al. [29] pyrolyzed Malaysian refuse derived fuels (RDF), a valuable portion of recycled waste, in a continuously stirred batch apparatus at $450{ }^{\circ} \mathrm{C}$ both with and without catalysts. They found increased isomerization of the main carbon chains as well as increased aromatic content in the product when Y-zeolite and ZSM-5 were applied. Mihalcik et al. [30] employed pyrolysis/gas chromatography-mass spectrometry (Py/GC-MS) to study the catalytic fast pyrolysis of lignocellulosic biomass samples consisting of oak, corn cob, corn stover, and switchgrass, as well as the fractional components of biomass: cellulose, hemicellulose, and lignin. They found that, among the various catalysts, HZSM-5 was the most effective at producing aromatic hydrocarbons from the pyrolytic vapors. They also demonstrated the manner in which the $\mathrm{Si} / \mathrm{Al}$ ratios of the catalysts play a role in the deoxygenation of the vapors, a step in the reaction pathway to aromatic hydrocarbons.

Williams and Nugranad [32] pyrolyzed rice husks with zeolite ZSM-5 catalyst during upgrading of the pyrolysis vapors in a fluidized bed reactor. Polycyclic aromatic hydrocarbons (PAHs) were present at low concentrations in the resulting bio-oils and increased in concentration with increasing pyrolysis temperature. Oxygenated compounds in the bio-oils were primarily phenols, cresols, benzenediols, and guaiacol and their alkylated derivatives. The application of the catalyst significantly reduced the yield of bio-oil, although the oxygen content of the oil was reduced with the formation of coke on the catalyst. The molecular weight distribution of the bio-oils decreased following catalysis and was further decreased with increasing catalysis temperature. The bio-oils resulting from catalysis exhibited significantly increased concentrations of both single ring aromatics and PAHs compared with oils produced by uncatalyzed biomass pyrolysis. The concentrations of both aromatic and polycyclic aromatic species increased with increasing catalyst temperature.

Pan et al. [34] pyrolyzed Nannochloropsis sp. (a type of green microalgae) residue using HZSM- 5 as the catalyst in a fixed-bed reactor. The results indicated that the bio-oil obtained from catalytic pyrolysis had lower oxygen content (19.5 wt $\%)$ and higher heating value $(32.7 \mathrm{MJ} / \mathrm{kg})$ compared with that obtained from direct uncatalyzed pyrolysis, which had an oxygen content of $30.1 \mathrm{wt} \%$ and a heating value of $24.6 \mathrm{MJ} / \mathrm{kg}$. The bio-oils from direct pyrolysis consisted primarily of long-chain carbon compounds with various terminal groups, while the catalytic pyrolysis products were chiefly aromatic hydrocarbons.

Zhang et al. [36] carried out the catalytic pyrolysis of corncobs, using HZSM-5 and sand as the fluidized bed material. After the catalytic pyrolysis, the oxygen content in the bio-oil was reduced by more than $25 \%$, and the oil fraction had a high heating value (HHV) of $34.6 \mathrm{MJ} / \mathrm{kg}$, which is close to the values of both diesel and heavy fuel oil. As shown in Table 3, the use of HZSM-5 led to a remarkable increase in aromatic hydrocarbons in the oil fraction, with a concurrent decrease in all other types
Table 3

Composition of the oil fraction following corncob pyrolysis (wt\%) [36].

\begin{tabular}{lcc}
\hline \multirow{2}{*}{ Component } & \multicolumn{2}{c}{ Composition of the collected liquid (wt\%) } \\
\cline { 2 - 3 } & Without catalyst & With HZSM-5 \\
\hline Acids & 3.72 & 0.22 \\
Esters & 2.24 & not available \\
Aldehydes & 8.56 & 3.05 \\
Alcohols & 4.14 & 1.13 \\
Ketones & 16.86 & 4.29 \\
Aliphatic hydrocarbons & 0.21 & not available \\
Aromatic hydrocarbons & 7.62 & 74.22 \\
Phenols & 38.61 & 7.56 \\
Unidentified & 18.04 & 9.53 \\
\hline
\end{tabular}

of compounds. Stephanidis et al. [41] examined the upgrading of lignocellulosic biomass (beech wood) pyrolysis vapors and also found that aromatics and PAHs were significantly increased by the use of HZSM-5 catalyst.

\subsection{Different types of ZSM-5}

The particular type of ZSM-5 which is employed during pyrolysis will influence the bio-oil properties. ZSM-5 zeolites having a wide range of pore size, shape, and acidity have been tested in a number of research projects. Jae et al. [22] investigated the influence of zeolite pore size and shape selectivity on the conversion of glucose to aromatics. This study determined that the aromatic yield was a function of the pore size of the zeolite catalyst, and that the pyrolysis of glucose over small pore zeolites did not produce any aromatics but rather gave oxygenated products, $\mathrm{CO}, \mathrm{CO}_{2}$, and coke as the major products. The highest aromatic yields were obtained from medium pore zeolites with pore sizes in the range of $0.52-0.59 \mathrm{~nm}$. High coke yield, low aromatic yields, and low oxygenate yields were observed with large pore zeolites, suggesting that the large pores facilitate the formation of coke. In addition to pore size, internal pore space and steric hindrance play a major role in the production of aromatics during pyrolysis. Medium pore zeolites with moderate internal pore space and steric hindrance (ZSM-5 and ZSM-11) exhibited the highest aromatic yields and the least amount of coke formation. The kinetic diameters of the products and reactants were estimated, to determine whether the reactions occur inside the pores or at external surface sites for the different zeolite catalysts. This analysis showed that the majority of the reactants and the aromatic products can fit inside the zeolite pores of most of the medium and large pore zeolites. However, on some ZSM- 5 zeolites with smaller pores, the polycyclic aromatics may be formed by secondary reactions on the catalyst surface, either directly or via reaction of smaller aromatics.

The pore structure and active sites of the catalyst can be tuned to control the product selectivity. Foster et al. [25] investigated the conversion of glucose, furan, and maple wood over different types of ZSM-5 catalysts in semi-batch and fixed-bed reactors. The aromatic yield from glucose conversion goes through a maximum as a function of the silica-to-alumina ratio (SAR) of the ZSM-5 framework, reaching a maximum at an SAR 
of 30 . This suggests that the concentration of acid sites inside the zeolite is critical for maximizing aromatic yields. Creating hierarchical mesopores within the zeolite slightly increased coke formation and decreased monocyclic aromatics formation. Mesoporous ZSM-5 was also observed to favor the production of larger alkylated monoaromatics. The selective removal of external acid sites from the ZSM-5 catalysts only slightly increased the catalyst's activity, while decreasing its selectivity for the desired aromatic products.

Stefanidis et al. [38] experimented with the in-situ catalytic upgrading of biomass vapors via fast pyrolysis in a fixed-bed bench-scale reactor at $500{ }^{\circ} \mathrm{C}$. Among various commercial ZSM-5 formulations, the ZSM-5 with the highest surface area exhibited the most balanced performance, displaying a moderate selectivity for hydrocarbons, reducing undesirable reaction byproducts, and producing organic liquid products at acceptable yields. Liu et al. [40] investigated the catalytic reforming of pyrolytic intermediates from the co-pyrolysis of pubescens and low density polyethylene (LDPE) over both ZSM-5 and the desilicated version of the zeolite (DeZSM-5) and proposed that the formation of aromatics was favored primarily by the presence of strong acid sites on the catalyst, while the production of alkanes was favored by weak acid sites.

\subsection{Comparisons between ZSM-5 and other catalysts}

To screen for effective biomass pyrolysis catalysts, many different types of catalyst have been studied. Uzun et al. [23] conducted both non-catalytic and catalytic rapid pyrolysis of corn stalks in a tubular fixed-bed reactor, using catalysts such as ZSM-5, HY, and USY under optimum conditions. The maximum bio-oil yield of $27.55 \%$ was obtained with ZSM-5, whereas the lowest bio-oil yield resulted from the use of USY, which also gave the highest proportion of aromatics among the catalysts used.

The yields of the pyrolysis products were slightly influenced by the catalyst structures, while the chemical composition of the bio-oil was dependent on the structure of the acidic zeolite catalysts. Aho et al. [24] carried out studies of the catalytic pyrolysis of biomass from pine wood in a fluidized bed reactor at $450{ }^{\circ} \mathrm{C}$, in which different structures of acidic zeolite catalysts were used as bed material in the reactor. The proton forms of beta, Y, ZSM-5, and mordenite were tested as catalysts in the pyrolysis of pine, while quartz sand was used as a reference material in the non-catalytic pyrolysis experiments. The formation of ketones was higher over ZSM-5 and the amounts of acids and alcohols lower than over the other bed materials tested. Mordenite and quartz sand produced smaller quantities of PAHs than the other materials tested. This work also determined that the spent zeolites could be successfully regenerated without changing the zeolite structures.

Pattiya et al. [26] found that zeolites, proprietary commercial catalysts, copper chromite, and biomass-derived ash were applicable to the selective reduction of most oxygenated lignin derivatives. The use of ZSM-5, Criterion-534, and Al-MSU-F catalysts enhanced the formation of aromatic hydrocarbons and phenols while both ZSM-5 and Al-MSU-F produced signifi- cant quantities of acetic and formic acids. No single catalyst was found to selectively reduce all the carbonyl products, although most of the carbonyl compounds containing hydroxyl group were reduced by the zeolites, proprietary catalysts, and copper chromite with zeolite.

Giannakopoulou et al. [28] tested three types of zeolite catalysts (HZSM-5, Fe-ZSM-5, and H-Beta) in the catalytic co-conversion of rapeseed cake and safflower oil into bio-oil. Upon catalytic upgrading at $400{ }^{\circ} \mathrm{C}$, the yields of bio-oil were 63.0, 59.4, and 58.8 wt $\%$ when using H-Beta, HZSM-5, and Fe-ZSM-5, respectively.

Miskolczi et al. [29] found pyrolyzed refuse-derived fuels produced gases, pyrolytic oils, and water at yields of 15.7\%-27.8\%, 9.8\%-17.8\%, and $9.2 \%-12.8 \%$, respectively, depending on the catalyst. The volatile fraction (composed of both the gases and pyrolytic oils) increased slightly with the application of a catalyst, especially in the case of Y-zeolite or ZSM-5. The major chemical components of the pyrolytic oils, including aromatics and both branched and non-branched alkanes, were found to vary depending on the particular catalyst employed. As an example, increased isomerization of the main carbon skeletons and increased production of aromatics were noted, especially when Y-zeolite and ZSM-5 were applied. The catalysts examined in this study were observed to decrease the concentration of impurities in the product mixture in the following order: $\mathrm{Ni}$-Mo-catalyst $>$ Co-Mo-catalyst $>$ Y-zeolite $>$ FCC $>\mathrm{ZSM}-5>\mathrm{Al}_{2} \mathrm{O}_{3} / \mathrm{SiO}_{2}>\mathrm{Al}_{2} \mathrm{O}_{3}$.

Wang et al. [31] investigated the pyrolysis of herb residues in a fixed-bed to determine the effects of both pyrolysis temperature and catalyst (using ZSM-5, Al-SBA-15, and alumina) on the product yields and the quality of the resulting bio-oils. The results indicated that the maximum bio-oil yield of $34.26 \%$ was obtained at $450{ }^{\circ} \mathrm{C}$ with $10 \mathrm{wt} \%$ alumina catalyst loading. It was also determined that addition of any of the catalysts both decreased the oxygen content and increased the heat value of the bio-oil product. $\mathrm{Al}_{2} \mathrm{O}_{3}$ was the most effective catalyst with regard to upgrading the pyrolytic oil, followed by Al-SBA-15 and ZSM-5. The bio-oil with the lowest oxygen content $(26.71 \%)$ and the highest heat value $(25.94 \mathrm{MJ} / \mathrm{kg})$ was obtained using a $20 \mathrm{wt} \%$ alumina catalyst loading. This catalyst was also shown to significantly increase the formation of both aliphatic and aromatic products.

Fabbri et al. [33] studied the effects of a variety of catalyst types, including zeolites ( $\mathrm{HY}, \mathrm{NH}_{4}-\mathrm{Y}$, and $\mathrm{NH}_{4}-\mathrm{ZSM}-5$ ) and metal oxides nanopowders $\left(\mathrm{SiO}_{2}, \mathrm{Al}_{2} \mathrm{O}_{3}, \mathrm{MgO}, \mathrm{TiSO}_{4}\right.$, and $\left.\mathrm{Al}_{2} \mathrm{O}_{3}-\mathrm{TiO}_{2}\right)$ on the pyrolytic production of chiral anhydrosugars from cellulose. The results showed that zeolites decreased the amount of anhydrosugars produced, whereas metal oxides nanopowders, with exception of $\mathrm{SiO}_{2}$, increased their production. $\mathrm{Al}_{2} \mathrm{O}_{3}-\mathrm{TiO}_{2}$ in particular increased the production of levoglucosan and levoglucosenone. Lappas et al. [27] employed a mixture of ZSM-5, USY, and silica as the circulating fluidized bed material, an approach which improved both the quality and the composition of the resulting bio-oils.

Pütün et al. [37] investigated the upgrading of rapid pyrolysis vapors over various catalysts (clinoptilolite (a natural zeolite, NZ), ZSM-5, and HY). Catalytic treatment with synthetic 
zeolites led to enhancement of the gas yields with concurrent reduction of the oil yields and a high catalyst to feed ratio was also found to favor increased gas yields. In this work, ZSM-5 was very effective at gas production, whereas the NZ was better suited to producing bio-oil in the absence of any significant level of coking, as compared with the synthetic zeolites, while HY exhibited a pronounced tendency to form coke and tar. In general, the application of the catalysts led to increased yields of aliphatics, aromatics, and olefins and a sharp decrease in the production of asphaltenes and highly oxygenated, polar functional groups. NZ was determined to be very effective in increasing aliphatic production, whereas ZSM-5 produced more aromatics. Stefanidis et al. [38] also found that zirconia/titania and ZSM-5 catalysts can assist in both reducing the oxygen content and increasing the aromatics content of the liquid organic products.

Park et al. [39] carried out the catalytic upgrading of pyrolytic vapors derived from radiata pine sawdust over mesoporous MFI zeolite, HZSM-5, and mesoporous material from HZSM-5 (MMZzSM-5). The mesoporous MFI zeolite exhibited the highest activity for deoxygenation and aromatization during the upgrading process. In particular, this zeolite showed pronounced selectivity for highly valuable aromatics such as benzene, toluene and xylenes (BTX), even though it decreased the overall organic fraction of the bio-oil. The incorporation of gallium into the mesoporous MFI zeolite increased both the organic fraction of the bio-oil and resistance to coke deposition. Moreover, the selectivity for BTX aromatics was enhanced when the appropriate amount of gallium was introduced.

Stephanidis et al. [41] worked on the upgrading of lignocellulosic biomass (beech wood) pyrolysis vapors using HZSM-5, silicalite, and Al-MCM-41 catalysts. They found that all the catalysts, especially the strongly acidic HZSM-5 zeolite, reduced the oxygen content of the organic fraction, primarily by decreasing the concentration of acids, ketones and phenols in the untreated biomass pyrolysis oil or the concentration of sugars in the pretreated biomass pyrolysis oil.

Among the various catalysts which have been applied to bio-oil upgrading, HZSM-5, which offers the advantageous properties of shape selectivity, ion exchange capacity, a three dimensional pore structure, and unique solid acidic characteristics, exhibited the overall best performance related to the production of aromatic hydrocarbons during deoxygenation.

\section{Catalytic cracking of bio-oil}

Due to the highly complex nature of bio-oils, understanding the reaction pathways associated with the conversion of each constituent compound is very helpful during the process of screening potential catalysts and processes. The complexity of elucidating these reaction mechanisms can be simplified by first studying model compounds. Literature reports concerning the catalytic pyrolysis of various model compounds and bio-oils, conducted under different reaction conditions, are summarized in Table 4.

\subsection{Model compounds}

Although many researchers [20-41] have used zeolites to convert biomass-derived feedstocks into aromatics, little is known about the catalytic chemistry. Model compounds can help us understand the rather complicated reactions involved in zeolite catalysis.

Studies to date have shown that both furfural and furan are major intermediates products resulting from the catalytic fast pyrolysis of glucose and cellulose at $600{ }^{\circ} \mathrm{C}[21,22]$. These products can account for up to $40 \%$ of the carbon in the oxygenated products and so can be considered as good candidates for model compounds. Cheng and Huber [42] carried out the conversion of furan, as a model for cellulosic biomass, over HZSM-5 in a continuous-flow fixed-bed reactor. This work examined the effects of space velocity and temperature on furan conversion to assist in understanding the chemistry of biomass conversion inside zeolite catalysts. The major products resulting from furan conversion included $\mathrm{CO}, \mathrm{CO}_{2}$, allene, $\mathrm{C}_{2}-\mathrm{C}_{6}$ olefins, benzene, toluene, styrene, benzofuran, indene, and naphthalene. The selectivity for aromatics (benzene and toluene) and olefins (ethylene and propylene) decreased with increasing space velocity, while the selectivity for unsaturated hydrocarbons such as allene, cyclopentadiene, and aromatics increased. The product distribution contained significant proportions of olefins and $\mathrm{CO}$ at high temperatures $\left(650^{\circ} \mathrm{C}\right)$ but the reaction was selective for aromatics (benzene and toluene) at intermediate temperatures $\left(450-600{ }^{\circ} \mathrm{C}\right.$ ) and, at low temperatures

Table 4

Catalytic pyrolysis of bio-oils under varying reaction conditions.

\begin{tabular}{|c|c|c|c|}
\hline Feed & Catalyst & Temperature $\left({ }^{\circ} \mathrm{C}\right)$ & Ref. \\
\hline Furan & HZSM-5 & 600 & {$[42]$} \\
\hline Furfural & HZSM-5, Zn/HZSM-5 & $300-500$ & [43] \\
\hline Propanal & Desilicated HZSM-5 & 400 & {$[44]$} \\
\hline Oxygenates with methanol & HZSM-5 & 370 & {$[45]$} \\
\hline Methylcyclohexane and phenol & HZSM-5 & 350,450 & [46] \\
\hline Propanal & HZSM-5 & 400 & [47] \\
\hline Model bio-oil O-compounds with gasoline & Equilibrium catalyst and ZSM-5 & 535 & [48] \\
\hline Guaiacol and $n$-heptane, gasoline and guaiacol & HY, HZSM-5 & 450,535 & [49] \\
\hline$n$-Heptane and phenol & Mixtures of HY and HZSM-5 & 450 & [50] \\
\hline Pure compound solutions and bio-oil derived feeds & ZSM-5 & 600 & [54] \\
\hline Wood pyrolysis bio-oil & HZSM-5, HY, Silicalite, H-Mordenite, Silica-alumina & $290-410$ & {$[52,53]$} \\
\hline Wood pyrolysis bio-oil & HZSM-5, HY & $410-490$ & {$[54,55]$} \\
\hline Pine pyrolysis bio-oil & HZSM-5 & 380 & {$[56]$} \\
\hline
\end{tabular}


$\left(450{ }^{\circ} \mathrm{C}\right)$, benzofuran and coke contributed $60 \%$ of the carbon selectivity. Several different reactions were found to occur during the conversion of furan over zeolites. Some important reactions that were identified in this study include Diels-Alder condensation (such as the formation of benzofuran and water from two furans), decarbonylation (the formation of $\mathrm{CO}$ and allene from furan), oligomerization (the synthesis of olefins and aromatics plus hydrogen from allene), and alkylation (such as the reaction of furan and olefins). The product distribution was far removed from that expected from thermodynamic equilibrium. During the furan conversion, graphite-type coke was observed to form on the catalyst surface, causing the formation of aromatics and olefins to cease within 30 min of starting the on-stream process.

A study by Fanchiang and Lin [43] using furfural as a model for cellulose generated similar results to those described above. Furfural was converted into gasoline-type fuels via catalytic fast pyrolysis over HZSM-5-based catalysts in a continuous fixed-bed system. The first step in furfural conversion is the decarbonylation of furfural to form furan, followed by furan conversion to intermediates such as cyclohexene and 3,4-dimethylbenzaldehyde, in the ZSM-5 pores. These intermediates are subsequently available for transformation into aromatics, coke, light olefins and carbon oxides.

Bio-oils typically contain aldehydes which reduce their thermal stability, and so reducing the aldehyde content of a bio-oil will increase its stability [14]. Zhu et al. [44] investigated the conversion of propanal to gasoline-type molecules over a series of HZSM-5 catalysts with controlled mesoporosity generated by desilication. The product distribution resulting from propanal conversion was found to vary with the extent of catalyst desilication, such that increasing desilication gradually reduced the aromatization and cracking reactions, due to a reduction in the micropore fraction and the diffusion path length. Hoang et al. [47] studied the conversion of propanal over large $(2-5 \mu \mathrm{m})$ and small $(0.2-0.5 \mu \mathrm{m})$ crystallite HZSM-5 at $400{ }^{\circ} \mathrm{C}$ and atmospheric pressure. They concluded that the use of smaller crystallite HZSM-5 improves the results of the process by increasing the production of alkyl aromatics from light oxygenates under mild conditions that may prove useful for bio-oil upgrading.

The adsorption of coke on the catalyst causes the blockage of the zeolite pores and thus decreases the catalyst's lifetime. Hence, significant research has focused on mitigating this problem. Mentzel et al. [45] performed the zeolite catalyzed deoxygenation of small oxygenates present in bio-oil or selected as model compounds under methanol-to-hydrocarbons (MTH)-like reaction conditions, using HZSM-5 as the catalyst. The co-feeding of oxygenates with methanol generally decreased coking and resulted in higher selectivity for aromatics compared with the conversion of pure methanol. Mentzel's group observed that particular acid and ester functionalities favor oxygen removal by promoting decarbonylation over dehydration, which preserves hydrogen in the hydrocarbon product mixture. By employing ${ }^{13} \mathrm{C}$ labeled substrates they confirmed the incorporation of carbon into the hydrocarbon products as well as a pronounced preference of the additive carbon for incorporation into aromatic compounds. This work also found that methanol dilution resulted in extended catalyst lifetimes.

To simulate the catalytic cracking of biomass-derived oils, Graça et al. [46] carried out the transformation of mixtures of methylcyclohexane and small amounts of phenol over an HZSM-5 zeolite at 350 and $450{ }^{\circ} \mathrm{C}$. They found that the main cause of deactivation is the strong adsorption of phenol molecules on the acid sites of the zeolite, resulting in simultaneous blocking of both active sites and pores. This phenomenon could result from the small average pore size of the ZSM-5, which slows down the diffusion of phenol molecules and facilitates their adsorption and retention.

This group also worked with several key oxygenated compounds, modeling many of the major oxygenated groups, including acetic acid, hydroxyacetone, and phenol, mixed with a standard gas oil and tested under fluid catalytic cracking (FCC) conditions [48]. They found that the effect of the ZSM-5 additive was attenuated in the presence of these chemicals, suggesting some form of interaction between such compounds and ZSM-5. It was also determined that up to $10 \mathrm{wt} \%$ of these compounds could be processed in the FCC unit without major problems, with the exception of phenol. In other trials, guaiacol was chosen as a model compound to ascertain its effects on the FCC process [49]. This work involved the transformation of $n$-heptane in the presence of small quantities of guaiacol over pure $\mathrm{HY}$ and HZSM- 5 zeolites at $450^{\circ} \mathrm{C}$, under which conditions the addition of guaiacol was shown to increase methane yield concurrent with its transformation into phenol. The addition of guaiacol also had a negative influence on the conversion process, however, since it led to an increase in the amount of coke retained on the catalysts. In subsequent research [50], $n$-heptane was transformed in the presence of phenol to evaluate the behavior of FCC catalysts during the co-processing of phenol-rich bio-oils and conventional FCC feedstocks over mixtures of $\mathrm{HY}$ and HZSM-5 zeolites at $450{ }^{\circ} \mathrm{C}$. This work found that, when the zeolites are mixed, the HY provides the HZSM-5 with increased resistance to phenol poisoning, thus reducing the detrimental effects of phenol on the HZSM-5 zeolite.

Zhang et al. [51] performed the catalytic conversion of ten different biomass-derived feedstocks (glucose, sorbitol, glycerol, tetrahydrofuran, methanol, and different hydrogenated bio-oil fractions) with different effective ratios of hydrogen to carbon $\left(\mathrm{H} / \mathrm{C}_{\text {eff }}\right)$ in a gas-phase flow fixed-bed reactor using a ZSM-5 catalyst. The aromatic/olefin carbon yield exhibited an increase with increases in the $\mathrm{H} / \mathrm{C}_{\text {eff }}$ ratio, while reduced $\mathrm{H} / \mathrm{C}_{\text {eff }}$ ratio feedstocks produced more coke, which rapidly deactivated the zeolite catalyst.

\subsection{Bio-oils}

Bio-oils may contain thousands of different organic compounds [2] and the catalytic upgrading of these oils is thus a complicated process. Adjaye and Bakhshi $[52,53]$ examined the upgrading of a fast pyrolysis bio-oil using different catalysts in a fixed-bed micro-reactor. After catalytic upgrading, the bio-oil yield decreased significantly and the hydrocarbon yields in the 
organic distillate fraction were found to vary with the particular catalyst employed in the following order: HZSM-5 (27.9 $w t \%)>$ HY $(14.1 w t \%)>$ silica-alumina $(13.2 w t \%)>$ silicalite (5 $\mathrm{wt} \%)>\mathrm{H}$-mordenite (4.4 wt\%). In addition, there was a significant difference between the catalysts in regard to selectivity for hydrocarbons; HZSM-5 and H-mordenite catalysts produced more aromatic hydrocarbons than aliphatics, whereas HY, silicalite and silica-alumina catalysts produced more aliphatics than aromatics. In other words, the acidic zeolites HZSM-5, HY and H-mordenite appeared to more effective in converting bio-oil to hydrocarbons than the less acidic silica-alumina and the non-acidic silicalite. In terms of the overall yield of hydrocarbons and aromatic hydrocarbons and resistance to coke formation, HZSM-5 was found to be the most effective catalyst. Consequently, the authors speculated that the conversion of bio-oil over catalysts proceeds as the result of thermal effects (the separation of the bio-oil into light organics and heavy organics, and the polymerization of bio-oil to char) followed by thermo-catalytic effects (deoxygenation, cracking, cyclization, aromatization, isomerization, and polymerization).

Vitolo et al. [54] examined the catalytic upgrading of raw pyrolytic bio-oils, using HZSM-5 and HY zeolites. The HZSM-5 catalyst produced highly deoxygenated oil with a very high heating value and good combustibility. In an additional study involving repeated regenerating cycles [55], wood pyrolysis oil was converted over HZSM-5 to highly deoxygenated, primarily aromatic oil. It was thus proposed that the active sites involved in the upgrading reactions are preferentially Brönsted acid sites acting through a carbonium ion mechanism to promote the deoxygenation, decarboxylation, and decarbonylation of the bio-oil, as well as cracking, oligomerization, alkylation, isomerization, cyclization, and aromatization. It was also observed that continued regeneration of HZSM- 5 at $500{ }^{\circ} \mathrm{C}$ in the presence of air resulted in the loss of a significant quantity of strong acidic sites, leading to decreased catalytic activity over the course of the conversion of biomass pyrolysis oils.

Guo et al. [56] upgraded bio-oil over HZSM-5 and characterized the precursors of coke on the catalyst. The coke precursors on the outer surface of the spent catalyst turned out to be saturated aliphatic hydrocarbons with boiling points below $200{ }^{\circ} \mathrm{C}$, while the coke deposits in the pores were mainly aromatic hydrocarbons, with boiling points ranging from 350 to $650{ }^{\circ} \mathrm{C}$. From these results, they concluded that deactivation of the catalyst was initiated from the inside, followed by pore blocking due to high molecular weight compounds. In experiments conducted over regenerated HZSM-5, a moderate change in the catalytic activity was observed during the first three regenerations, with the activity gradually decreasing thereafter.

Most of the studies mentioned above were focused on catalytic upgrading of bio-oils or typical bio-oil components as the starting feedstock. Reheating of the bio-oil generated by cooling gas products from biomass fast pyrolysis is required in these upgrading processes. This step leads to increased energy consumption and the formation of tar and/or char. As a result, in-situ catalytic cracking, where the pyrolytic vapors generated from biomass fast pyrolysis are directly upgraded before cooling appears a more promising approach. Integrated catalytic processing, for example, involving a combination of HZSM-5 catalytic pyrolysis with hydroprocessing, as well as the application of multifunctional catalysts for both biomass pyrolysis and bio-oil refining, is becoming an increasingly attractive technique for the production of fuels and chemicals.

\section{Conclusions}

This review focused on the catalytic pyrolysis of biomass and the catalytic cracking of bio-oils using HZSM-5 to improve the quality of the bio-oil, which has emerged as a potentially valuable renewable resource. Research thus far shows that, in catalytic upgrading, the bio-oil quality is strongly dependent on the properties of the catalyst, including its structure, acidity and pore sizes, as well as the type of feedstock and the reaction conditions. Among these factors, the acidity of the catalyst has been found to play the most critical role in upgrading reactions consisting of cracking, deoxygenation, oligomerization, cyclization, aromatization, alkylation, isomerization and polymerization. Among the wide variety of catalysts used in bio-oil upgrading, HZSM-5, which offers the advantages of shape selectivity, ion exchange capacity, a three dimensional pore structure and unique solid acidic characteristics, exhibited the best performance in terms of the production of aromatic hydrocarbons, deoxygenation and resistance to coke deposition. In addition, the application of a bi-functional metal, to increase the quantity of strong acid sites and the rates of dehydrogenation reactions necessary for the formation of aromatic hydrocarbons, can enhance both the production of high-quality bio-oil and the selectivity for aromatic hydrocarbons. In future, the problem of catalyst deactivation due to dealumination and coke deposition needs to be resolved, to prevent loss of the pronounced catalytic activities of HZSM-5 catalysts during bio-oil upgrading processing over long time periods. As well, the efficient conversion of biomass will require the development and application of multifunctional catalytic materials, such as catalysts capable of both deoxygenation and hydrogenation. Finally, the catalytic upgrading of biomass pyrolysis vapors appears to be one of the most attractive of the candidate methods for bio-oil upgrading, since this process allows the catalysis and pyrolysis temperatures to be varied independently, which assists in controlling the product distributions and selectivities.

\section{References}

[1] Demirbas A. Energy Convers Manage, 2009, 50: 2782

[2] Bulushev D A, Ross J R H. Catal Today, 2011, 171: 1

[3] Mohan D, Pittman C U Jr, Steele P H. Energy Fuels, 2006, 20: 848

[4] Zhang Zh J, Wang Q W, Yang X L, Chatterjee S, Pittman C U Jr. Bioresour Technol, 2010, 101: 3685

[5] Zhang Zh J, Wang Q W, Tripathi P, Pittman C U Jr. Green Chem, 2011, 13: 940

[6] Samolada M C, Baldauf W, Vasalos I A. Fuel, 1997, 77: 1667

[7] Williams P T, Horne P A. Fuel, 1995, 74: 1839

[8] Horne P A, Williams P T. Fuel, 1996, 75: 1043

[9] Lu Q, Dong C Q, Zhang X M, Tian H Y, Yang Y P, Zhu X F. J Anal Appl Pyrolysis, 2011, 90: 204

[10] Li D L, Nakagawa Y, Tomishige K. Chin J Catal (催化学报), 2012, 


\section{Graphical Abstract}

Chin. J. Catal., 2013, 34: 641-650 doi: 10.1016/S1872-2067(12)60531-2

\section{Recent progress of catalytic pyrolysis of biomass by HZSM-5}

TAN Shun, ZHANG Zhijun, SUN Jianping, WANG Qingwen * Northeast Forestry University; Shenyang Jianzhu University

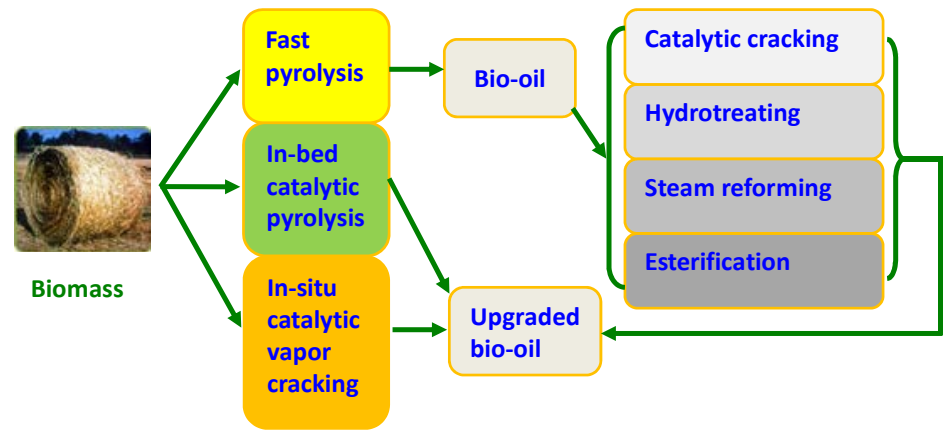

This review summarizes recent research regarding the catalytic pyrolysis of biomass and the catalytic cracking of bio-oils using HZSM-5 and related catalysts, and also provides a synopsis of potential future development of catalysts and processes in this area.

\section{3: 583}

[11] Liu H B, Chen T H, Zhang X L, Li J H, Chang D Y, Song L. Chin J Catal (刘海波, 陈天虎, 张先龙, 李金虎, 常冬寅, 宋否. 催化学报), 2010, 31: 409

[12] Song M, Zhong Z P, Dai J J. J Anal Appl Pyrolysis, 2010, 89: 166

[13] Zheng J L.J Anal Appl Pyrolysis, 2008, 83: 205

[14] Zhang Q, Chang J, Wang T J, Xu Y. Energy Convers Manage, 2007, 48: 87

[15] Ma L L, Wang T J, Liu Q Y, Zhang X H, Ma W C, Zhang Q. Biotechnol $A d v, 2012,30: 859$

[16] Mortensen P M, Grunwaldt J D, Jensen P A, Knudsen K G, Jensen A D. Appl Catal A, 2011, 407: 1

[17] Xiu S N, Shahbazi A. Renew Sust Energy Rev, 2012, 16: 4406

[18] Butler E, Devlin G, Meier D, McDonnell K. Renew Sust Energy Rev, 2011, 15: 4171

[19] Corma A, Iborra S, Velty A. Chem Rev, 2007, 107: 2411

[20] Pattiya A, Titiloye J O, Bridgwater A V. J Anal Appl Pyrolysis, 2008, 81: 72

[21] Carlson T R, Jae J, Lin Y C, Tompsett G A, Huber G W. J Catal, 2010, 270: 110

[22] Jae J, Tompsett G A, Foster A J, Hammond K D, Auerbach S M, Lobo R F, Huber G W. J Catal, 2011, 279: 257

[23] Uzun B B, Sarioğlu N. Fuel Process Technol, 2009, 90: 705

[24] Aho A, Kumar N, Eränen K, Salmi T, Hupa M, Murzin D Y. Fuel, 2008, 87: 2493

[25] Foster A J, Jae J, Cheng Y T, Huber G W, Lobo R F. Appl Catal A, 2012, 423-424: 154

[26] Pattiya A, Titiloye J O, Bridgwater A V. Fuel, 2010, 89: 244

[27] Zhao Y, Deng L, Liao B, Fu Y, Guo Q-X. Energy Fuels, 2010, 24: 5735

[28] Giannakopoulou K, Lukas M, Vasiliev A, Brunner C, Schnitzer H. Bioresour Technol, 2010, 101: 3209

[29] Miskolczi N, Borsodi N, Buyong F, Angyal A, Williams P T. Fuel Process Technol, 2011, 92: 925

[30] Mihalcik D J, Mullen C A, Boateng A A. J Anal Appl Pyrolysis, 2011, 92: 224
[31] Wang P, Zhan S H, Yu H B, Xue X F, Hong N. Bioresour Technol, 2010, 101: 3236

[32] Williams P T, Nugranad N. Energy, 2000, 25: 493

[33] Fabbri D, Torri C, Baravelli V. J Anal Appl Pyrolysis, 2007, 80: 24

[34] Pan P, Hu C W, Yang W Y, Li Y S, Dong L L, Zhu L F, Tong D M, Qing R W, Fan Y. Bioresour Technol, 2010, 101: 4593

[35] Lappas A A, Samolada M C, Iatridis D K, Voutetakis S S, Vasalos I A. Fuel, 2002, 81: 2087

[36] Zhang H Y, Xiao R, Huang H, Xiao G. Bioresour Technol, 2009, 100: 1428

[37] Pütün E, Uzun B B, Pütün A E. Energy Fuels, 2009, 23: 2248

[38] Stefanidis S D, Kalogiannis K G, Iliopoulou E F, Lappas A A, Pilavachi P A. Bioresour Technol, 2011, 102: 8261

[39] Park H J, Heo H S, Jeon J-K, Kim J, Ryoo R, Jeong K-E, Park Y-K. Appl Catal B, 2010, 95: 365

[40] Liu W W, Hu C W, Yang Y, Tong D M, Li G Y, Zhu L F. Energy Convers Manage, 2010, 51: 1025

[41] Stephanidis S, Nitsos C, Kalogiannis K, Iliopoulou E F, Lappas A A, Triantafyllidis K S. Catal Today, 2011, 167: 37

[42] Cheng Y T, Huber G W. ACS Catal, 2011, 1: 611

[43] Fanchiang W L, Lin Y C. Appl Catal A, 2012, 419-420: 102

[44] Zhu X L, Lobban L L, Mallinson R G, Resasco D E. J Catal, 2010, 271: 88

[45] Mentzel U V, Holm M S. Appl Catal A, 2011, 396: 59

[46] Graça I, Comparot J-D, Laforge S b, Magnoux P, Lopes J M, Ribeiro M F, Ramôa Ribeiro F. Energy Fuels, 2009, 23: 4224

[47] Hoang T Q, Zhu X, Lobban L L, Resasco D E, Mallinson R G. Catal Commun, 2010, 11: 977

[48] Graça I, Ribeiro F R, Cerqueira H S, Lam Y L, de Almeida M B B. Appl Catal B, 2009, 90: 556

[49] Graça I, Lopes J M, Ribeiro M F, Ramôa Ribeiro F, Cerqueira H S, de Almeida M B B. Appl Catal B, 2011, 101: 613

[50] Graça I, Lopes J M, Ribeiro M F, Badawi M, Laforge S, Magnoux P, Ramôa Ribeiro F. Fuel, 2012, 94: 571

[51] Zhang H Y, Cheng Y T, Vispute T P, Xiao R, Huber G W. Energy Environ Sci, 2011, 4: 2297 
[52] Adjaye J D, Bakhshi N N. Fuel Process Technol, 1995, 45: 161

[53] Adjaye J D, Bakhshi N N. Fuel Process Technol, 1995, 45: 185

[54] Vitolo S, Seggiani M, Frediani P, Ambrosini G, Politi L. Fuel, 1999, 78: 1147
[55] Vitolo S, Bresci B, Seggiani M, Gallo M G. Fuel, 2001, 80: 17

[56] Guo X Y, Zheng Y, Zhang B H, Chen J Y. Biomass Bioenergy, 2009, 33: 1469

\title{
HZSM-5上生物质催化裂解的近期研究进展
}

\author{
谭 顺 ${ }^{\mathrm{a}}$ ，张志军 ${ }^{\mathrm{a}}$ ，孙剑平 ${ }^{\mathrm{a}, \mathrm{b}}$ ，王清文 ${ }^{\mathrm{a}}{ }^{*}$ \\ a东北林业大学生物质材料科学与技术教育部重点实验室, 黑龙江哈尔滨 150040 \\ b沈阳建筑大学市政与环境工程学院, 辽宁沈阳 110168
}

摘要: 概述了近期的HZSM-5对生物质和生物油催化裂解的研究进展, 重点介绍了催化剂的应用、生物油提质的方法和反应机理. 关键词: 生物质; 生物油; 提质; 裂解; 热解; HZSM-5

收稿日期: 2012-11-10. 接受日期: 2013-01-07. 出版日期: 2013-04-20.

*通讯联系人. 电话: (0451)82191993; 传真: (0451)82191993; 电子信箱: qwwang@nefu.edu.cn

基金来源: 国家自然科学基金(31010103905).

本文的英文电子版由Elsevier出版社在ScienceDirect上出版(http://www.sciencedirect.com/science/journal/18722067). 